\title{
Induction of CTLs by DCs pulsed with K-ras mutant peptide on the surface of nanoparticles in the treatment of pancreatic cancer
}

\author{
GUANG TAN, ZHONGYU WANG, XIN ZHANG, ZHENGANG CAI and JUNKAI ZHANG
}

Department of General Surgery, The First Affiliated Hospital of Dalian Medical University, Dalian 116011, P.R. China

Received November 16, 2010; Accepted December 21, 2010

DOI: $10.3892 /$ or.2011.1283

\begin{abstract}
The aim of this study was to investigate the role of specific cytotoxic T lymphocytes (CTLs) activated by dendritic cells (DCs) presenting cationic nanoparticles with the K-ras (12-Val) mutant peptide in the killing of different pancreatic cancer cell lines in vivo and in vitro. Peripheral blood DCs were induced by rhGM-CSF and IL-4 and cultured. DCs were sensitized by whole antigen of PANC-1 with expression of K-ras mutant, K-ras mutant peptide (K-ras+peptide) and cationic nanoparticles with K-ras mutant peptide (K-ras+peptide-CNP), respectively. Cell surface markers were measured by flow cytometry. Lymphocyte proliferation was detected by the ${ }^{3} \mathrm{H}-\mathrm{TdR}$ test, and IL-12 and IFN- $\gamma$ secretion was detected by ELISA. ${ }^{125} \mathrm{I}-\mathrm{UdR}$ was used to measure the killing effect of CTLs. The antitumor activity of CTLs in tumor-bearing nude mouse models prepared with PANC-1 and SW1990 cells was evaluated. Results showed that, compared with K-ras+peptide, low concentrations of K-ras+peptide-CNP were effectively presented by DCs $(\mathrm{P}<0.05)$. CTLs induced by DCs pulsed with whole tumor antigen had a significantly greater killing effect $(\mathrm{P}<0.05)$ on PANC-1 and SW1990 pancreatic cancer cells compared with K-ras+peptide- and K-ras+peptide-CNP-induced CTLs. CTLs induced by DCs pulsed with K-ras+peptide and K-ras+peptide$\mathrm{CNP}$ had a specific killing effect $(\mathrm{P}<0.05)$ on PANC-1 cells and no effect $(\mathrm{P}>0.05)$ on SW1990 cells. In conclusion, cationic nanoparticles with the K-ras (12-Val) mutant peptide can be
\end{abstract}

Correspondence to: Dr Zhongyu Wang, Department of General Surgery, The First Affiliated Hospital of Dalian Medical University, No. 222, Zhongshan Road, Dalian 116011, P.R. China

E-mail: fishflowers@hotmail.com

Abbreviations: CTLs, cytotoxic T lymphocytes; DCs, dendritic cells; $\mathrm{mDC}$, mature dendritic cell; GM-CSF, granulocyte-macrophage colony-stimulating factor; IL, interleukin; CNP, cationic nanoparticles; APCs, antigen-presenting cells; SI, stimulating index; TNF- $\alpha$, tumor necrosis factor; PBS, phosphate-buffered saline; PBMCs, peripheral mononuclear cells; IFN- $\gamma$, interferon- $\gamma$; FCS, fetal calf serum; ELISA, enzyme-linked immunosorbent assay

Key words: pancreatic cancer, dendritic cells, K-ras peptide, antigen, cationic nanoparticles, cytotoxic T lymphocytes, mutation effectively presented by DCs at a low concentration. CTLs induced by K-ras+peptide-CNP had specific killing activity for the pancreatic cancer cell line with the K-ras mutant and significantly inhibited tumor growth and increased the survival time of tumor-bearing nude mice. Although this study confirmed that whole cell antigen induced a good antitumor immune response, the possibility of immune tolerance and autoimmunity which has been previously proven contribute to the difficulty in the application of this DC vaccine.

\section{Introduction}

Pancreatic cancer accounts for 1-5\% of all malignant tumors (1). Its incidence has shown a clear upward trend in recent years with 230,000 new cases of pancreatic cancer each year worldwide (2). Pancreatic cancer lacks specific clinical manifestations. The surgical resection rate of pancreatic cancer is less than $20 \%$, and it is not sensitive to radiotherapy or chemotherapy. The 5-year survival rate is less than 5\%. The prognosis of pancreatic cancer has not improved in the last 20 years $(3,4)$. Immunotherapy for pancreatic cancer mainly includes specific active immunotherapy, monoclonal antibody-directed therapy, cytokine therapy and adoptive cellular immunotherapy (5). Dendritic cells (DCs) are known to be the most powerful antigen presenting cells (APCs) in the human body $(6,7)$. Studies have found that the K-ras gene mutation rate in pancreatic cancer patients was approximately $90 \%$ and that the gene mutation site was the ideal target for DC immunotherapy. In this study, we investigated the effects of DCs sensitized with different antigens and the killing effect of induced specific CTLs on different pancreatic cancer cell lines in vivo and in vitro.

\section{Materials and methods}

Materials. PANC-1 and SW1990 cell lines were purchased from ATCC. The cationic polymer $\beta(1,4)$-2-amino-2-deoxyD-glucan was purchased from Sigma (USA). Human recombinant GM-CSF and IL-4 were purchased from R\&D Systems (USA), and mouse anti-human CD80-PE, CD83-PE, CD86-PE, CD40-FITC, CD1a-FITC monoclonal antibodies were obtained from Immunotech (France). Ficoll (lymphocyte separation medium) was purchased from Second Plant of 
Shanghai Biochemical Reagents, and FCS was from Hyclone (USA). Iscove's modified Dulbecco's medium (IMDM) was from Gibco (USA). ${ }^{3} \mathrm{H}-\mathrm{TdR}$ and ${ }^{125} \mathrm{I}-\mathrm{UdR}$ were purchased from the Institute of Atomic Energy, China, and the flow cytometer was from BD Biosciences. The 550 microplate reader was from Bio-Rad. IL-12 and IFN- $\gamma$ ELISA kits were purchased from Jingmei Co., Shenzhen, and the K-ras (12-Val) mutant peptide antibody was from Bayer Co. The K-ras mutant peptide KLVVVGAVGVGKSALTC (8) was synthesized by Saibaisheng Genentech, Beijing. BALB/c nude mice (5-8 weeks old, female) were purchased from the Shanghai Animal Center of Chinese Academy of Sciences and housed in a specific pathogen-free (SPF) environment.

Preparation of antigen and cell culture. The pancreatic cancer cell lines PANC-1 (with point mutations of K-ras, K-ras ${ }^{+}$) (9) and SW1990 (without point mutations of K-ras, K-ras') were cultured in IMDM medium with $10 \% \mathrm{FCS}$ at $37^{\circ} \mathrm{C}$ under $5 \%$ $\mathrm{CO}_{2}$. After culturing for $72 \mathrm{~h}$, passaging was performed. One week later, the cells were digested with trypsin containing $2 \%$ EDTA and washed twice with PBS. The supernatant was discarded, and the cells were counted. The concentration of PANC-1 cells was adjusted to $2 \times 10^{7} / \mathrm{ml}$. The cells were frozen and thawed three times in liquid nitrogen and at $37^{\circ} \mathrm{C}$, respectively. Centrifugation for $5 \mathrm{~min}$ at $100,000 \mathrm{rpm}$ and filter sterilization were performed to prepare whole tumor cell antigen. Cationic polymer $\beta(1,4)-2$-amino-2-deoxy-D-glucan $0.2 \%(\mathrm{w} / \mathrm{v})$ was dissolved in sodium acetate $(\mathrm{pH} 5.0)$. Then, K-ras epitope peptide KLVVVGAVGVGKSALTC was added, and the mixture was heated to $50-55^{\circ} \mathrm{C}$. The liquid was mixed by magnetic force stirring, and cationic nanoparticles with the K-ras mutant peptide were prepared.

Separation of mononuclear cells. Fasting venous blood $(20 \mathrm{ml})$ from a normal donor was collected under sterile conditions (the same sample was used in repeated experiments) and diluted with PBS at a 1:1 ratio. Mononuclear cells were separated from the lymphocyte separation medium (10), and a cell suspension was produced. A final concentration of $2 \times 10^{6}$ cells $/ \mathrm{ml}$ was incubated for $2 \mathrm{~h}$ at $37^{\circ} \mathrm{C}$ under $5 \% \mathrm{CO}_{2}$ in an incubator. Then adherent cells were washed three times with IMDM. Non-adherent cells were washed away and collected for freezing. Adherent cells were scraped and used as monocytes.

Induction of imDC, mature ( $m) D C$ and antigen loading. Mono-cytes were cultured with cytokines $(1,000 \mathrm{U} / \mathrm{ml}$ rhGM-CSF, $500 \mathrm{U} / \mathrm{ml} \mathrm{rhIL-4)} \mathrm{(11),} \mathrm{and} \mathrm{half} \mathrm{concentrations} \mathrm{of}$ cytokines were added every other day. On the fifth day, the following antigens were added: i) whole tumor cell antigen with tumor cells and DCs at a ratio of 1:10; ii) K-ras mutant antigen peptide (K-ras+peptide) $(2.5,5.0,10.0$ and $20.0 \mu \mathrm{g} /$ $\mathrm{ml})$; iii) cationic nanoparticles (CNP) with K-ras mutant antigen peptide (K-ras+peptide-CNP) $(2.5,5.0,10.0$ and $20.0 \mu \mathrm{g} / \mathrm{ml}$ ); and iv) culture medium as control. The cells were cultured at $37^{\circ} \mathrm{C}$ in $5 \% \mathrm{CO}_{2}$. The medium was changed after 2 days, and TNF- $\alpha(10 \mu \mathrm{g} / \mathrm{ml})$ was added for $48 \mathrm{~h}$. The cell supernatant was collected.

Morphological observation of DCs pulsed with K-ras +peptide$C N P$. The morphology of DCs was observed under scanning and transmission electron microscopy after being sensitized by K-ras+peptide-CNP.

Detection of surface molecules of DCs. DCs induced by the different antigens were collected and centrifuged at $1500 \mathrm{rpm}$ for $10 \mathrm{~min}$. The cells were washed three times with PBS, incubated at $37^{\circ} \mathrm{C}$ for $30 \mathrm{~min}$, and washed with PBS once more. FITC-rat anti-human CD80, CD83, CD86, CD1a, HLA-DR and K-ras (12-Val) mutant peptide antibodies were added. Fluorescent-labeled isotype Ig was used as the control. Flow cytometry was used for detection.

Detection of T lymphocyte proliferation. Lymphocytes were obtained from the same blood donors (separation method as described above). A total of $2 \times 10^{5} /$ well lymphocytes and $2 \times 10^{4} /$ well DCs loaded with the different antigens was mixed in 96 -well plates and cultured at $37^{\circ} \mathrm{C}$ under $5 \% \mathrm{CO}_{2}$ for 5 days. ${ }^{3} \mathrm{H}-\mathrm{TdR}(37 \mathrm{kBq} / \mathrm{hole})$ was added for $12 \mathrm{~h}$. Cells were collected, and the cpm value was measured with a liquid scintillation counter. The stimulating index (SI) was calculated: $\mathrm{SI}=($ experimental $\mathrm{cpm}-$ background $\mathrm{cpm}) /($ control $\mathrm{cpm}-$ background $\mathrm{cpm}$ ).

Detection of CTL killing effect. The lymphocytes from the proliferation assay $\left(1 \times 10^{7}\right)$ were used as effector cells. A total of $1 \times 10^{6}$ tumor cells in the logarithmic growth phase were cultured with $5 \mu \mathrm{Ci}^{125} \mathrm{I}-\mathrm{UdR}$ and $5 \mathrm{~mol} 5$-fluorouracil. Complete culture medium was added to a final volume of $1 \mathrm{ml}$, and the cells were cultured in an incubator for $2 \mathrm{~h}$ at $37^{\circ} \mathrm{C}$ in $5 \% \mathrm{CO}_{2}$. The cells were washed three times with IMDM to remove unlabeled ${ }^{125} \mathrm{I}$-UdR. A $\gamma$-counter was used to determine the cell count. Cells with an average labeling rate $>1 \mathrm{cpm}$ were used as target cells. The target cells were adjusted to $5 \times 10^{5} / \mathrm{ml}$ with IMDM culture medium containing 10\% FCS. Effector and target cells were mixed at different ratios $(1: 6.25 ; 1: 12.5$; $1: 25 ; 1: 50$ ), and complete culture medium was added for a final volume of $1 \mathrm{ml}$ (set of 3 double tubes). A control group of target cells was used to determine the spontaneous release rate. The medium was centrifuged at 1,000 rpm for $3 \mathrm{~min}$ and cultured for $12 \mathrm{~h}$ at $37^{\circ} \mathrm{C}$ in $5 \% \mathrm{CO}_{2}$. After centrifugation at $2,000 \mathrm{rpm}$ for $5 \mathrm{~min}$, the cpm value was measured. Cytotoxic activity was expressed as the ${ }^{125} \mathrm{I}-\mathrm{UdR}$ release percentage: ${ }^{125} \mathrm{I}-\mathrm{UdR}$ release $\%=(\mathrm{cpm}$ value of experimental group - $\mathrm{cpm}$ value of spontaneous release)/(maximum release value of cpm cpm value of spontaneous release) x $100 \%$.

\section{Animal experiments}

Establishment of a tumor-bearing mouse model. PANC-1 and SW1990 cells in the logarithmic growth phase were suspended at a concentration of $1 \times 10^{7}$ cells $/ \mathrm{ml}$. Then, $0.2 \mathrm{ml}$ of the cell suspension was inoculated subcutaneously into each BALB/ c-nude mouse, and the survival time of the nude mice was observed. Ten days after inoculation, the mice were divided randomly into 5 groups with 10 mice in each group: i) whole cell antigen group which were injected with whole tumor antigeninduced CTLs, ii) K-ras+peptide-CNP group which was injected with K-ras+peptide-CNP-induced CTLs, iii) K-ras+peptide group which was injected with K-ras+peptide-induced CTLs, and iv) the control group injected with normal saline. Subsequently, $2 \times 10^{6}$ of the various antigen-induced CTLs were 


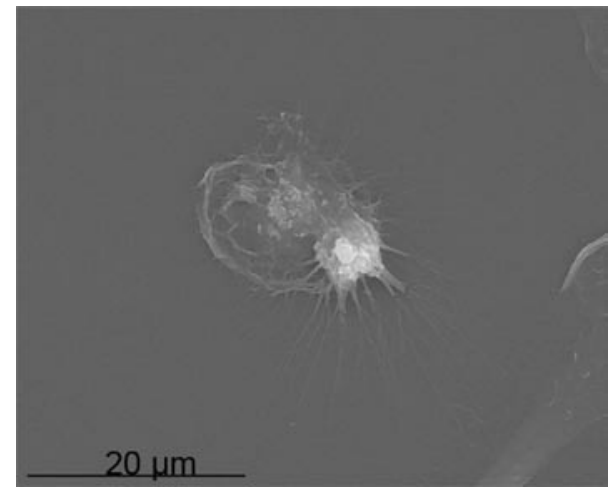

Figure 1. Morphological alterations of DCs on Day 7 (post-loading) of culturing under scanning electron microscopy. The cells exhibited a very irregular shape, and the processes varied widely, being either dendritic or petal-shaped.

injected intraperitoneally every other day for 10 consecutive days. Before injection, the long (L) and short (S) diameters of the tumors were measured. The tumor size was estimated by $\mathrm{V}=$ $\left(\mathrm{L} \times \mathrm{S}^{2}\right) / 2(12)$. The survival time of the mice was monitored.

Statistical analysis. SPSS16.0 statistical software was used for statistical analysis. The measurement data were presented as mean $\pm \mathrm{SD}$. The raw data underwent tests for homogeneity of variance before t-test and variance analysis with $\mathrm{P}<0.05$ as a statistically significant difference.

\section{Results}

Morphological observation. Four days after culturing, the DCs appeared in large clusters with a short thorn-like process at the surface of the cells. As time progressed, suspended cells gradually increased, and the thorn-like process increased, showing a flocculus-like shape characteristic of a typical dendritic cell.

DCs on Day 7 (post-loading) of culturing were observed under scanning electron microscopy. The cells exhibited a very irregular shape, and the processes varied widely, being either dendritic or petal-shaped (Fig. 1). Under transmission electron microscopy, after loading, dendritic or petal-shaped processes increased significantly with a clear nucleus, rich organelles, numerous mitochondria, rich rough endoplasmic reticulum and rare lysosomes (Fig. 2).

Expression of cell surface markers by DCs loaded with different antigens. The expression levels of cell surface markers, CD1a, CD80, CD83 and HLA-DR, by DCs pulsed with whole tumor antigen were significantly higher than those of mature DCs $(\mathrm{P}<0.001)$. Cell surface marker expression by DCs pulsed with K-ras+peptide and K-ras+peptide-CNP was not significantly different (P>0.05). CD1a, CD80, CD83 and HLA-DR expression in DCs pulsed with whole tumor antigen was significantly higher than that in the K-ras+peptide and K-ras+peptide-CNP groups $(\mathrm{P}<0.05)$. CD1a, CD80, CD83 and HLA-DR expression by DCs loaded with K-ras+peptide and K-ras+peptide-CNP was significantly higher than $\mathrm{mDCs}(\mathrm{P}<0.05)$, and CD86 expression between the groups showed no significant difference $(\mathrm{P}>0.05)$ (Table I).

Detection of the K-ras mutant antigen peptide presented by DCs. The antigen presenting capability of DCs was measured by flow cytometry using the K-ras mutant monoclonal antibody (12-Val). After being treated with $5 \mu \mathrm{g} / \mathrm{ml} \mathrm{K}$-ras+peptide-CNP, the antigen-presenting rate of DCs was $55.85 \%$. No significant difference in the presenting capability of DCs was found when compared with the DCs treated with $10 \mu \mathrm{g} / \mathrm{ml} \mathrm{K-ras+peptide-}$ CNP (56.13\%) (P>0.05) (Fig. 3A). Similarly, the presenting capability of DCs was not significantly different when they were treated with high concentrations of antigens (10 and $20 \mu \mathrm{g} / \mathrm{ml})(\mathrm{P}>0.05)$. However, at low concentrations (2.5 and $5 \mu \mathrm{g} / \mathrm{ml}$ ), the antigen-presenting rate of DCs in the K-ras+ peptide-CNP group was significantly higher than that of the K-ras+peptide group $(\mathrm{P}<0.05)$ (Fig. 3B).

Effect of different antigens on the production of IL-12 by DCs. After treatment with low concentrations $(2.5,5$ and $10 \mu \mathrm{g} / \mathrm{ml})$ of K-ras+peptide and K-ras+peptide-CNP, the production of IL-12 by DCs in the K-ras+peptide-CNP group was significantly higher than that of the K-ras+peptide group $(\mathrm{P}<0.05)$. The production of IL-12 by DCs showed no significant difference when treated with high concentrations of antigen (P>0.05) (Fig. 4A). DCs loaded with different antigens had significant differences in IL-12 secretion levels $(\mathrm{P}<0.05)$. DCs of the tumor cell antigen group produced the highest levels of
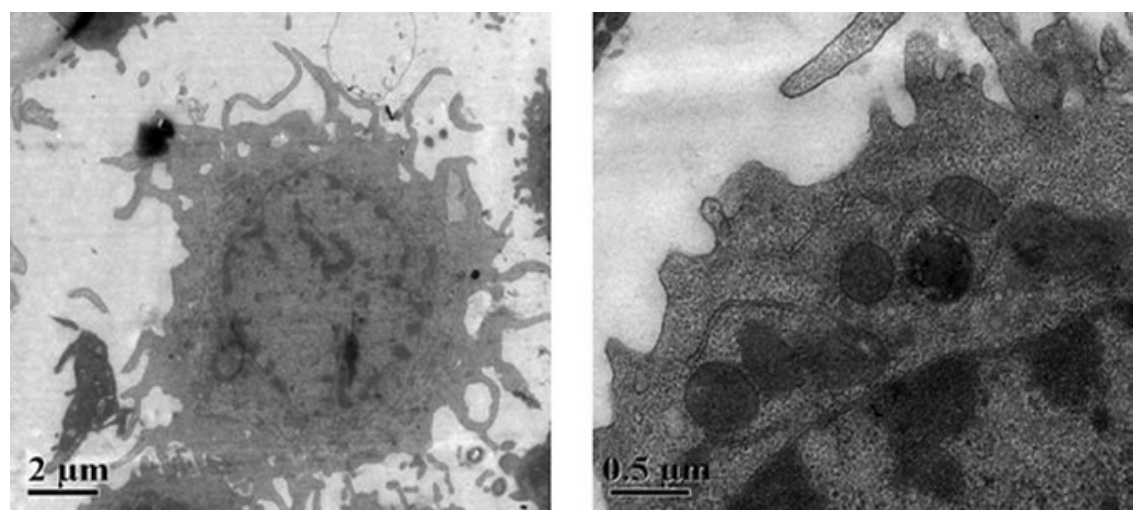

Figure 2. Morphological alterations of DCs on Day 7 (post-loading) of culturing under transmission electron microscopy. Dendritic or petal-shaped processes increased significantly with a clear nucleus, rich organelles, numerous mitochondria, rich rough endoplasmic reticulum and rare lysosomes. 
Table I. Surface markers of DCs induced by different antigens (\% positive cells, mean \pm SD, $n=6$ ).

\begin{tabular}{lccccc}
\hline Groups & CD1a & CD80 & CD83 & CD86 & HLA-DR \\
\hline mDC & $22.6 \pm 3.6$ & $49.4 \pm 3.2$ & $38.5 \pm 4.6$ & $72.6 \pm 5.6$ & $66.5 \pm 4.6$ \\
DC (tumor, T:DC=1:10) & $55.2 \pm 4.5$ & $82.6 \pm 4.9$ & $76.3 \pm 5.1$ & $80.9 \pm 6.7$ & $93.2 \pm 5.8$ \\
DC (K-ras+peptide, $10 \mu \mathrm{g} / \mathrm{ml}$ ) & $35.1 \pm 4.3$ & $62.2 \pm 5.8$ & $51.1 \pm 4.9$ & $74.4 \pm 5.2$ & $82.4 \pm 4.4$ \\
DC (K-ras+peptide-CNP, $5 \mu \mathrm{g} / \mathrm{ml})$ & $38.4 \pm 3.7$ & $67.5 \pm 4.7$ & $58.4 \pm 6.3$ & $75.3 \pm 4.8$ & $86.1 \pm 5.3$ \\
\hline
\end{tabular}

DC (tumor, T:DC=1:10) vs. mDC, $\mathrm{P}<0.001$ except CD86; DC (K-ras+peptide, $10 \mu \mathrm{g} / \mathrm{ml})$ and DC (K-ras+peptide-CNP, $5 \mu \mathrm{g} / \mathrm{ml}) \mathrm{vs} . \mathrm{mDC}$, $\mathrm{P}<0.05$ except CD86; DC (tumor, T:DC=1:10) vs. DC (K-ras+peptide, $10 \mu \mathrm{g} / \mathrm{ml}$ ) and DC (K-ras+peptide-CNP, $5 \mu \mathrm{g} / \mathrm{ml}$ ), $\mathrm{P}<0.05 \mathrm{except} \mathrm{CD} 86$.

A
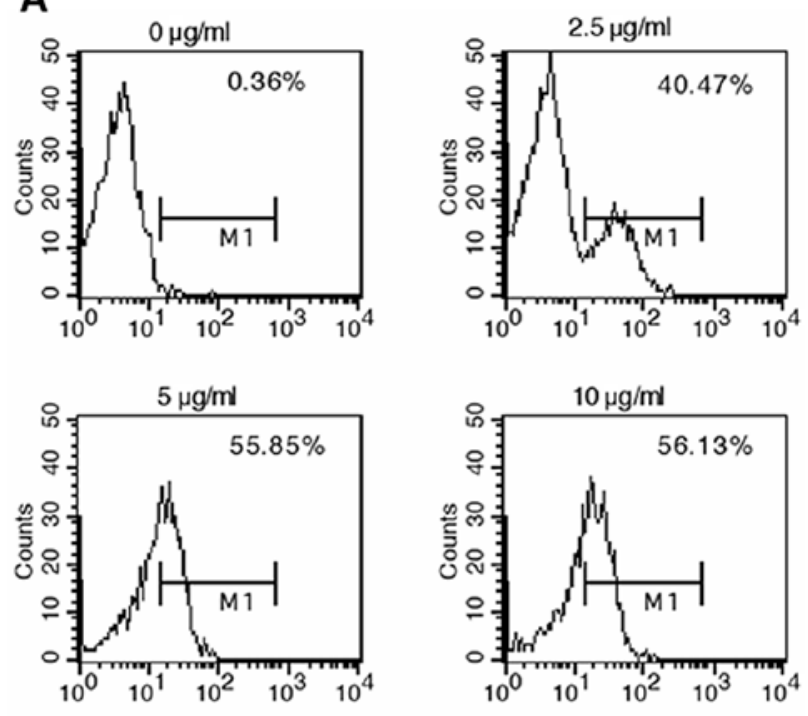

K-ras+peptide-CNP

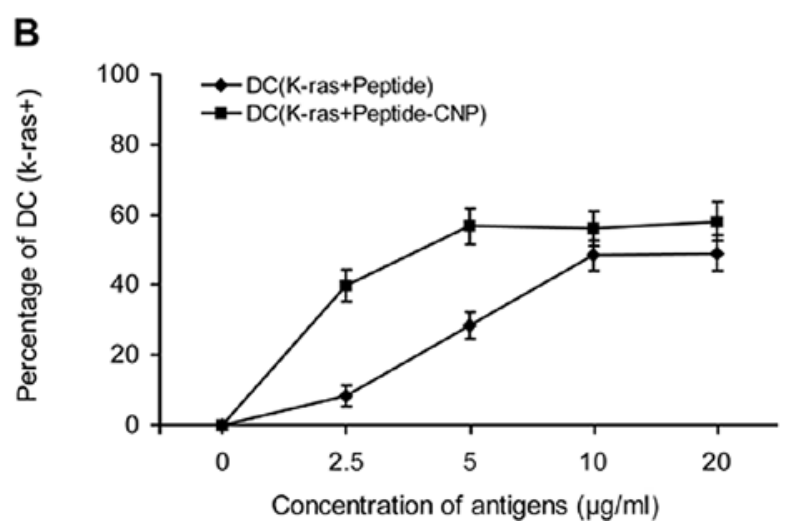

Figure 3. Effect of DC loading with different concentrations of K-ras+peptide and K-ras+peptide-CNP by flow cytometry. (A) After being treated with $5 \mu \mathrm{g} / \mathrm{ml} \mathrm{K-ras+peptide-CNP}$, the antigen-presenting rate of DCs was $55.85 \%$. No significant difference in the presenting capability of DCs was found compared with DCs treated with $10 \mu \mathrm{g} / \mathrm{ml} \mathrm{K-ras+peptide-CNP} \mathrm{(56.13 \% )}$ $(P>0.05)$. (B) Similarly, the presenting capability of DCs was not significantly different when they were treated with high concentrations of antigens (10 and $20 \mu \mathrm{g} / \mathrm{ml})(\mathrm{P}>0.05)$. However, at low concentrations $(2.5$ and $5 \mu \mathrm{g} / \mathrm{ml})$, the antigen presenting rate of DCs in the K-ras+peptide-CNP group was significantly higher than that of the K-ras+peptide group $(\mathrm{P}<0.05)$

IL-12, followed by the K-ras+peptide-CNP and K-ras+peptide groups, while mDCs secreted minimal IL-12 (Fig. 4B).
Effect of DCs loaded with different antigens on peripheral blood mononuclear cell (PBMC) proliferation and interferon (IFN)- $\gamma$ production. PBMC proliferation and IFN- $\gamma$ production induced by DCs loaded with whole tumor antigen were significant greater than when DCs from the other groups were used $(\mathrm{P}<0.01)$. Those in the K-ras+peptide-CNP group were greater than those of the K-ras+peptide and $\mathrm{mDC}$ groups $(\mathrm{P}<0.05)$. The $\mathrm{K}$-ras+peptide group was greater than the $\mathrm{mDC}$ group $(\mathrm{P}<0.05)$, as shown in Fig. 5.

Effect of DCs loaded with different antigens on the activity of tumor-specific CTLs induced in vitro. CTLs induced by DCs loaded with PANC-1 total antigen had the strongest killing effect on PANC-1 cells. Compared with the K-ras+peptide-CNP and K-ras+peptide groups, the P-value was $<0.05$. Compared with the mDC group, the P-value was $<0.01$. Among the CTLs induced by DCs loaded with K-ras+peptide-CNP and K-ras+ peptide, no significant difference was noted in the killing effect on PANC-1 cells ( $\mathrm{P}>0.05)$ but were significantly stronger than those of the mDC group $(\mathrm{P}<0.05)$. CTLs induced by DCs loaded with PANC-1 whole antigen had the strongest killing effect on SW1990 cells, which was significantly higher than in the other three groups $(\mathrm{P}<0.05)$. CTLs induced by DCs loaded with K-ras+peptide-CNP and K-ras+peptide did not have significantly different killing effects against SW1990 cells compared with the mDC group $(\mathrm{P}>0.05)$. These results indicated that CTLs induced by DCs loaded with the K-ras mutant epitope peptide were able to kill PANC-1 tumor cells with the K-ras mutant antigen but not SW1990 tumor cells without the K-ras mutant tumor antigen (Fig. 6).

Effect of CTLs induced by different tumor antigens on the survival time of tumor-bearing nude mice. A total of $2 \times 10^{6}$ CTLs induced by DCs loaded with different antigens were injected intraperitoneally, and the survival time of the nude mice was observed. The effects of the whole antigen group, $\mathrm{K}$-ras+peptide-CNP group and K-ras+peptide group on the survival time of PANC-1 tumor-bearing mice were significantly different compared with the control group $(\mathrm{P}<0.01)$ (Fig. 7A). Prolongation of survival time in the whole antigen group was most significant and was significantly different compared with the other two groups $(\mathrm{P}<0.05)$. No significant difference was found between the K-ras+peptide-CNP group and the $\mathrm{K}$-ras+peptide group $(\mathrm{P}>0.05)$. The effect of the whole antigen groups on the survival time of SW1900 tumor-bearing mice was significantly different compared with the K-ras+peptide- 
A

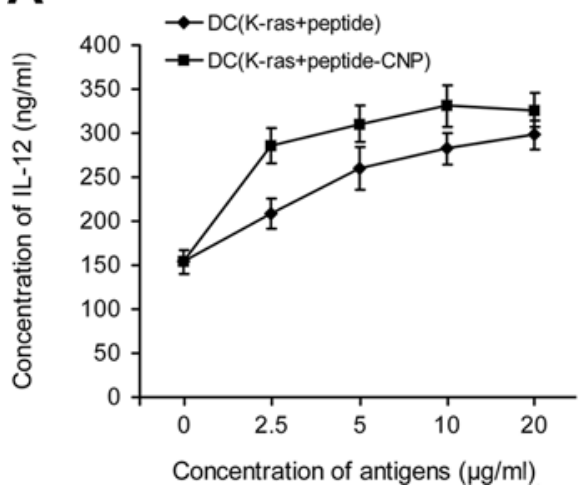

B

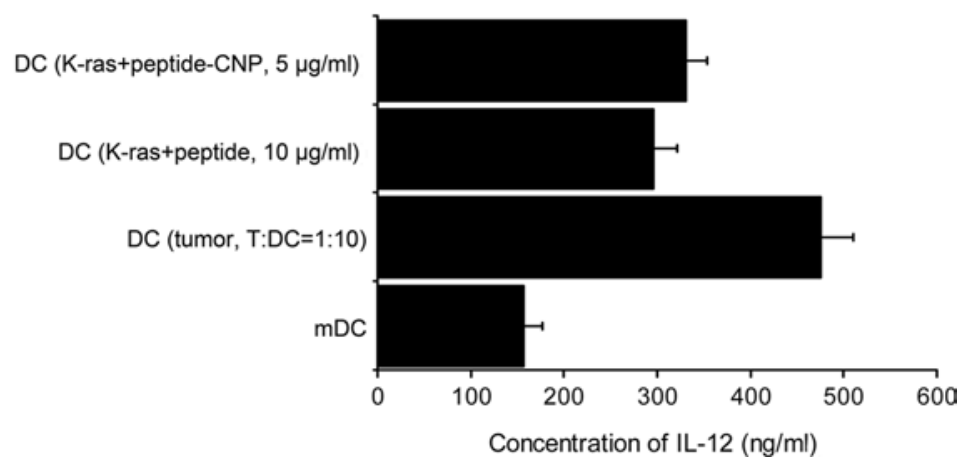

Figure 4. Effect of DC loading with different antigens on the production of IL-12. The production of IL-12 by DCs in the K-ras+peptide-CNP group was significantly higher than that of the K-ras+peptide group $(\mathrm{P}<0.05)$, yet no significant difference was noted when treated with a high concentration $(20 \mu \mathrm{g} / \mathrm{ml})$ of the antigen $(\mathrm{P}>0.05)(\mathrm{A})$. DCs of the tumor cell antigen group produced the highest levels of IL-12, followed by the K-ras+peptide-CNP and K-ras+peptide groups, while mDCs secreted minimal IL-12 (B).

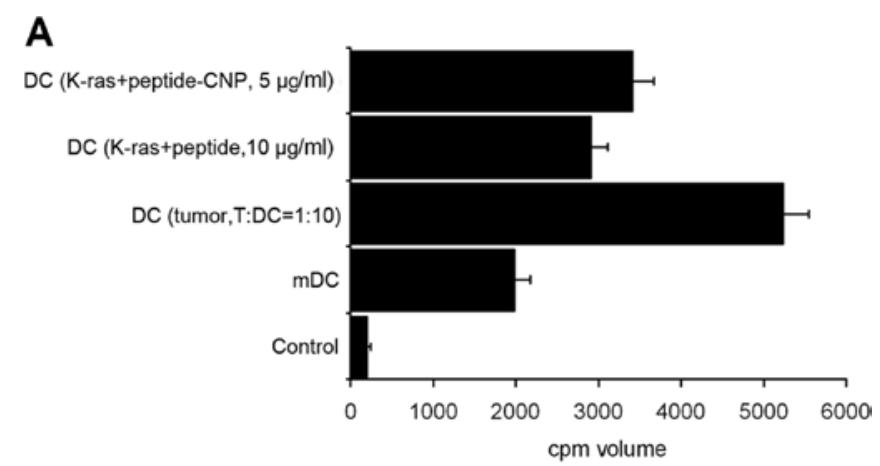

\section{B}

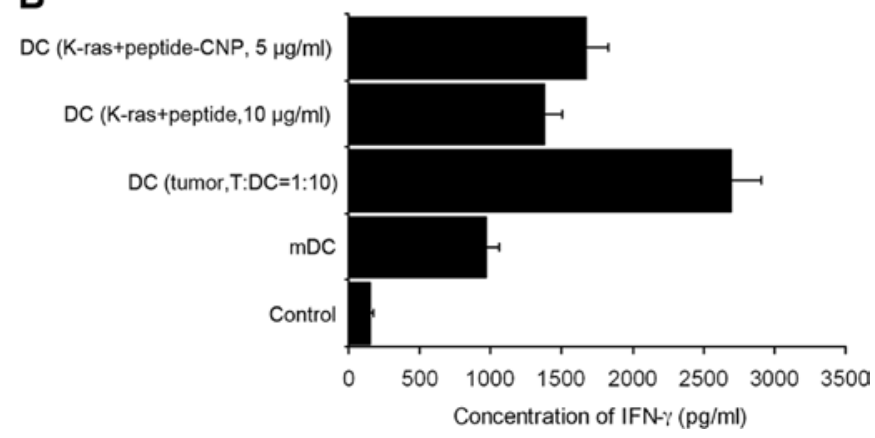

Figure 5. Effect of DC loading with different antigens on the (A) induction of proliferation and (B) IFN- $\gamma$ production in PBMCs. PBMC proliferation and IFN $-\gamma$ production induced by DCs loaded with whole tumor antigen were significant greater than when DCs from other groups were used $(\mathrm{P}<0.01)$. These effects in the K-ras+peptide-CNP group were greater than those of the $\mathrm{K}$-ras+peptide and mature DC groups $(\mathrm{P}<0.05)$.

CNP group, K-ras+peptide group and control group $(\mathrm{P}<0.01)$ (Fig. 7B). The mice had a prolonged survival time. There was no significant difference between the other groups $(\mathrm{P}>0.05)$. Both results showed that the CTLs induced by the K-ras mutant epitope peptide significantly prolonged the survival time of PANC-1 tumor-bearing mice.

\section{Discussion}

Approximately $10 \%$ of pancreatic cancer is caused by genetic susceptibility (13), of which most are due to gene mutations, including K-ras, CDKN2A, BRCA2, DPC4, p53, AKT2 and p16 (14-18). The K-ras gene is located on chromosome $12 \mathrm{p} 12$ and encodes the ras protein. The K-ras gene point mutation generally occurs in codons 12,13 and 61, with a highest mutation rate at codon 12 . Research has shown that the K-ras gene mutation rate in pancreatic cancer is approximately $90 \%$ (19). It has been found that a point mutation of codon 12 of the K-ras gene is an early event in pancreatic cancer (20). The clinical significance of the K-ras gene mutation for effective diagnosis of early pancreatic cancer may exceed imaging and cytology examination (21). Gene targeting and immunotherapy for codon 12 of the K-ras gene may aid in the diagnosis and treatment of pancreatic cancer (22).

Research in the biological treatment for tumors has confirmed that DC vaccines have significant value in the treatment of malignant tumors and infectious diseases. However, DCs require different forms of modification in vitro before the application of tumor therapy to activate and improve the quantity and quality of the DCs. These modifications include lysed tumor antigen, epitope peptides, RAN transfection, apoptosis of tumor cells, cytokines and heat shock proteins. At present, DCs are mainly derived from $\mathrm{CD} 34^{+}$hematopoietic stem cells or PBMCs (23).

In the present study, DCs were isolated and cultured from PBMCs using the traditional method. The typical morphology of DCs was shown under scanning and transmission electron microscopy. Immune analysis showed that after stimulation with different antigens (whole-cell antigen and the K-ras mutant antigen peptide), surface molecular markers of mature DCs appeared. Cation vector is a polymer material mainly used for enhancing gene transfection efficiency. We found that the cation vector combined with antigen peptide enhanced the phagocytosis of the antigen into the DCs and increased the antigen load of the DCs, which may be related to molecular size and release ability (24). The epitope can be presented at an early stage, but, with the increase in the epitope concentration, the presented epitopes at the surface of the DCs did not increase significantly, which may be due to the promotion of DC phagocytosis by the cationic carrier rather than the presenting function. Thus, when the loaded antigen was saturated, increasing the antigen did not cause an increase in epitopes. Research on the 
A

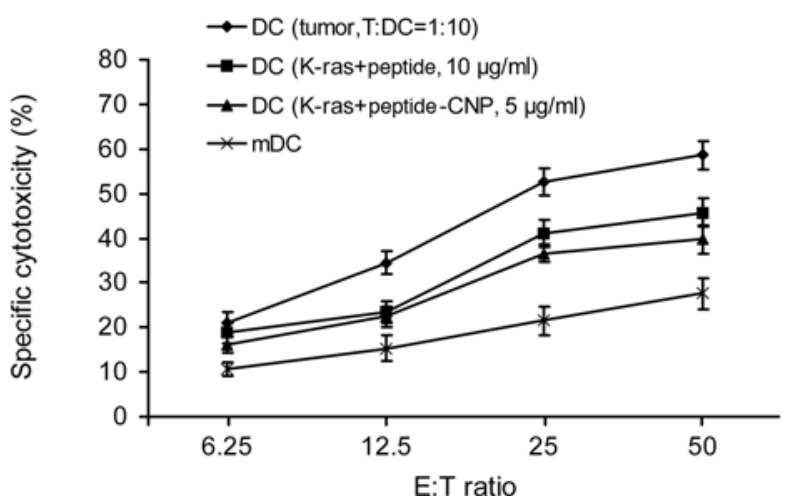

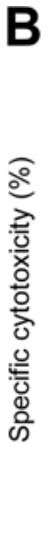

SW1990 cells (K-ras-)

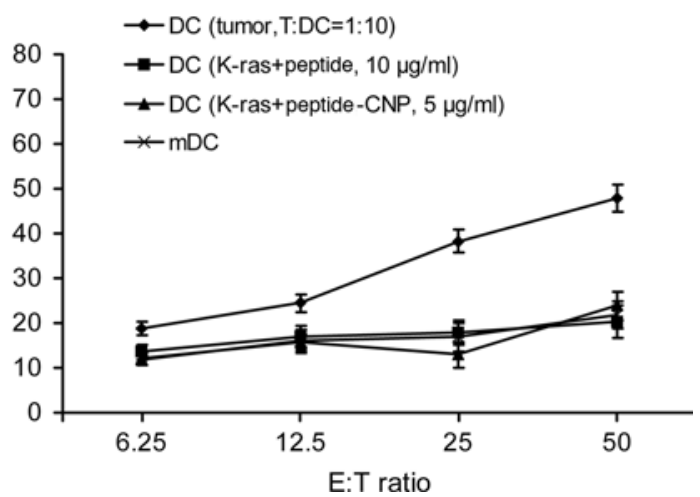

Figure 6. Effect of DC loading with different antigens on the induction of tumor-specific CTL cytotoxicity against (A) PANC-1 (K-ras ${ }^{+}$) and (B) SW1990 cells (K-ras') in vitro. CTLs by DCs loaded with PANC-1 total antigen had the strongest killing effect on PANC-1 cells. Compared with the K-ras+peptide-CNP and K-ras+peptide groups, the P-value was $<0.05$. Compared with the mDC group, the P-value was $<0.01$. CTLs by DCs loaded with PANC-1 whole antigen had the strongest killing effect on SW1990 cells. CTLs by DCs loaded with K-ras+peptide-CNP, K-ras+peptide and mDC did not exhibit a significant killing effects against SW1990 cells.

A

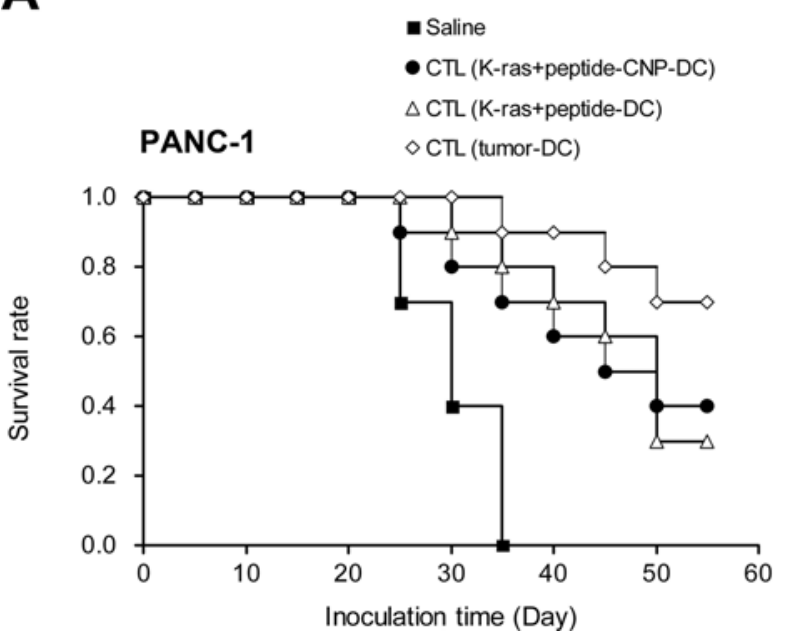

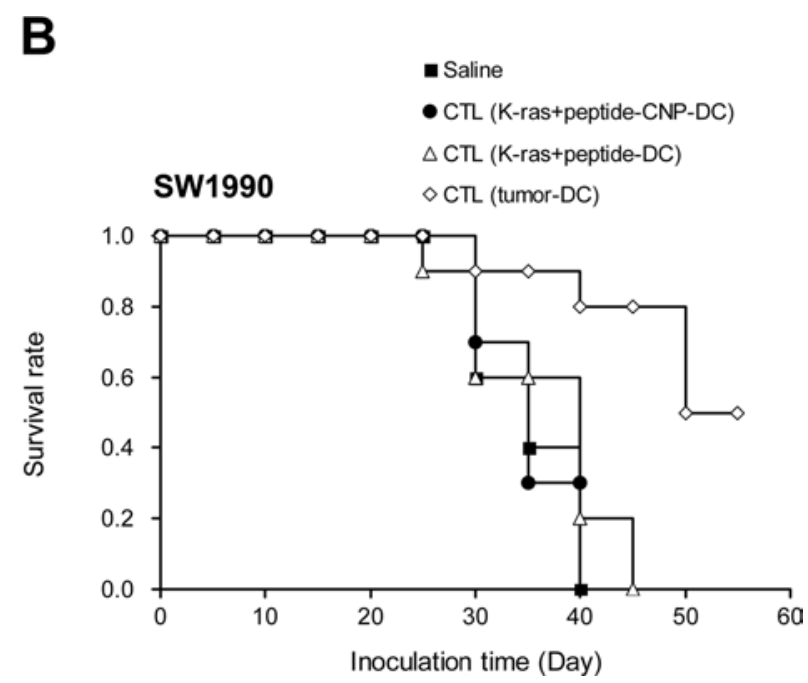

Figure 7. Survival of nude mice inoculated subcutaneously in the back with PANC-1 and SW1990 cells after immunotherapy with CTLs induced by DCs loaded with different antigens. Prolongation of survival time in the whole antigen group was most significant and was significantly different compared with the other two groups $(\mathrm{P}<0.05)(\mathrm{A})$. The effect of the whole antigen groups on the survival time of SW1900 tumor-bearing mice was significantly different compared with the K-ras+peptide-CNP group, K-ras+peptide group and control group ( $\mathrm{P}<0.01)(\mathrm{B})$.

K-ras mutant peptide as a loading antigen has been reported. Pure peptide is easily degraded, which limits its application. A relatively low amount of peptide can saturate the presenting DCs, while a large amount of antigen can easily cause immune tolerance. A small amount of cationic nanoparticles with K-ras mutant antigen peptides can be phagocytized and presented at an early stage, which is very important in immune therapy for cancer. These nanoparticles may be a new method for loading DCs with an antigen, and the antigen is specific with less cross-reactivity. The advantages of this method are unparalleled. It can significantly promote the proliferation and cytotoxic activity of CTLs compared with CTLs induced by DCs modified with ordinary peptide, which may be related to the promotion of IL-12 secretion by DCs and increased immune activity $(25,26)$. To confirm the specificity of the immune response of CTLs induced by DCs pulsed with specific tumor antigen, PANC-1 cells with the K-ras gene mutation and SW1990 cells without the K-ras gene mutation were used (9). The results showed that CTLs induced by DCs sensitized by the K-ras antigen had a specific cytotoxic effect on PANC-1 cells but no significant inhibition of SW1990 cells $(\mathrm{P}<0.05)$. Therefore, DC vaccines loaded with the K-ras point mutation antigen peptide are important in specific immunotherapy for pancreatic cancer patients with a ras gene mutation.

Of the three types of antigens, whole cell antigen had the greatest impact on the DCs. It promoted higher expression of surface mature molecules of DCs (CD80, CD83, CD86, HLA-DR, CD1a), which may be due to the complexity of its antigen components and a higher level of cancer antigen. In 
the present study, we found that CTLs induced by DCs loaded with PANC-1 cell antigen demonstrated strong cytotoxic effects not only on PANC-1 cells but also on SW1990 cells. Many effective antigens in PANC-1 cells, including K-ras protein, were phagocytized and presented by DCs in this experiment; one or a variety of antigens was the effective recognition component of SW1990 cells by CTLs. Thus, DCs sensitized by PANC-1 cell antigen have a greater therapeutic effect on SW1990 pancreatic cancer cells in vivo and in vitro. Although this study confirmed that whole cell antigen induced an ideal antitumor immune response, it contained the normal cellular components, which make immune tolerance and autoimmunity possible. Additionally, the tumor antigen content cannot be easily controlled, which causes difficulty in the application of DC-sensitized antigen (27-29).

In the present study, whole tumor cell antigen-, K-ras+peptideand K-ras+peptide-CNP-sensitized DCs promoted the expression of surface molecules of mature DCs and enhanced the cytotoxic activity of CTLs on target cells, IL-12 secretion by DCs and IFN- $\gamma$ secretion by T cells. All CTLs induced by the three types of antigen were able to kill target cells effectively. $\mathrm{K}$-ras+peptide-CNP- and K-ras+peptide-sensitized DCs exhibited more specificity for the target cells. Sensitization by K-ras+peptide-CNP was more effective than K-ras+peptide. In vivo experiments also support these results, which lay the foundations for the future development of DC vaccines for pancreatic cancer.

\section{Acknowledgements}

The study was sponsored by the Nature Science Foundation of China (NSFC) (30670624, 30870719).

\section{References}

1. Jemal A, Siegel R, Ward E, Murray T, Xu J and Thun MJ: Cancer statistics, 2007. CA Cancer J Clin 57: 43-66, 2007.

2. Chiang KC and Chen TC: Vitamin D for the prevention and treatment of pancreatic cancer. World J Gastroenterol 15: 3349-3354, 2009.

3. Mendieta Zeron H, Garcia Flores JR and Romero Prieto ML: Limitations in improving detection of pancreatic adenocarcinoma. Future Oncol 5: 657-668, 2009.

4. Koliopanos A, Avgerinos C, Farfaras A, Manes C and Dervenis C: Radical resection of pancreatic cancer. Hepatobiliary Pancreat Dis Int 7: 11-18, 2008.

5. Kawakami Y, Okada T and Akada M: Development of immunotherapy for pancreatic cancer. Pancreas 28: 320-325, 2004.

6. Riccobon A, Ridolfi R and Galassi R: Migration of dendritic cells to regional lymph nodes in a vaccination trial. Cancer Cell Int 2: 27, 2004

7. Timmerman JM, Czerwinski DK, Davis TA, et al: Idiotypepulsed dendritic cell vaccination for B-cell lymphoma: clinical and immune responses in 35 patients. Blood 99: 1517-1526, 2002.

8. Gjertsen MK, Bakka A, Breivik J, et al: Vaccination with mutant ras peptides and induction of T-cell responsiveness in pancreatic carcinoma patients carrying the corresponding RAS mutation. Lancet 346: 1399-1400, 1995.

9. Aoki K, Yoshida T, Matsumoto N, Ide H, Sugimura T and Terada M: Suppression of Ki-ras p21 levels leading to growth inhibition of pancreatic cancer cell lines with Ki-ras mutation but not those without Ki-ras mutation. Mol Carcinog 20: 251-258, 1997.
10. Elkord E, Williams PE, Kynaston $\mathrm{H}$ and Rowbottom AW: Human monocyte isolation methods influence cytokine production from in vitro generated dendritic cells. Immunology 114: 204-212, 2005.

11. Eljaafari A, Li YP and Miossec P: IFN-gamma, as secreted during an alloresponse, induces differentiation of monocytes into tolerogenic dendritic cells, resulting in FoxP $3^{+}$regulatory $\mathrm{T}$ cell promotion. J Immunol 183: 2932-2945, 2009.

12. Mikata K, Uemura H, Ohuchi H, Ohta S, Nagashima $Y$ and Kubota Y: Inhibition of growth of human prostate cancer xenograft by transfection of $\mathrm{p} 53$ gene: gene transfer by electroporation. Mol Cancer Ther 1: 247-252, 2002.

13. Lynch HT, Smyrk T, Kern SE, et al: Familial pancreatic cancer: a review. Semin Oncol 23: 251-275, 1996.

14. Pellegata NS, Sessa F, Renault B, Bonato M, Leone BE, Solcia E and Ranzani GN: K-ras and p53 gene mutations in pancreatic cancer: ductal and non-ductal tumors progress through different genetic lesions. Cancer Res 54: 1556-1560, 1994

15. Whelan AJ, Bartsch D and Goodfellow PJ: Brief report: a familial syndrome of pancreatic cancer and melanoma with a mutation in the CDKN2 tumor-suppressor gene. N Engl J Med 333: 975-977, 1995.

16. Goggins M, Hruban RH and Kern SE: BRCA2 is inactivated late in the development of pancreatic intraepithelial neoplasia: evidence and implications. Am J Pathol 156: 1767-1771, 2000.

17. Hahn SA, Schutte M, Hoque AT, et al: DPC4, a candidate tumor suppressor gene at human chromosome 18q21.1. Science 271: 350-353, 1996.

18. Eskelinen MJ and Haglund UH: Prognosis of human pancreatic adenocarcinoma: review of clinical and histopathological variables and possible uses of new molecular methods. Eur J Surg 165: 292-306, 1999.

19. Koorstra JB, Hustinx SR, Offerhaus GJ and Maitra A: Pancreatic carcinogenesis. Pancreatology 8: 110-125, 2008.

20. Ji B, Tsou L, Wang H, et al: Ras activity levels control the development of pancreatic diseases. Gastroenterology 137: 1072-1082, 1082 e1071-1076, 2009.

21. Dabritz J, Preston R, Hanfler J and Oettle H: Follow-up study of K-ras mutations in the plasma of patients with pancreatic cancer: correlation with clinical features and carbohydrate antigen 19-9. Pancreas 38: 534-541, 2009.

22. Fleming JB, Shen GL, Holloway SE, Davis M and Brekken RA: Molecular consequences of silencing mutant K-ras in pancreatic cancer cells: justification for K-ras-directed therapy. Mol Cancer Res 3: 413-423, 2005.

23. Nestle FO, Farkas A and Conrad C: Dendritic-cell-based therapeutic vaccination against cancer. Curr Opin Immunol 17: 163-169, 2005.

24. Tyagi RK, Sharma PK, Vyas SP and Mehta A: Various carrier system(s)- mediated genetic vaccination strategies against malaria. Expert Rev Vaccines 7: 499-520, 2008.

25. Koido S, Hara E, Homma S, et al: Streptococcal preparation OK-432 promotes fusion efficiency and enhances induction of antigen-specific CTL by fusions of dendritic cells and colorectal cancer cells. J Immunol 178: 613-622, 2007.

26. Isomura I, Yasuda Y, Tsujimura K, Takahashi T, Tochikubo K and Morita A: Recombinant cholera toxin B subunit activates dendritic cells and enhances antitumor immunity. Microbiol Immunol 49: 79-87, 2005.

27. Toh HC, Wang WW, Chia WK, et al: Clinical benefit of allogeneic melanoma cell lysate-pulsed autologous dendritic cell vaccine in MAGE-positive colorectal cancer patients. Clin Cancer Res 15: 7726-7736, 2009.

28. Katial RK, Brandt BL, Moran EE, Marks S, Agnello V and Zollinger WD: Immunogenicity and safety testing of a group B intranasal meningococcal native outer membrane vesicle vaccine. Infect Immun 70: 702-707, 2002.

29. Gil M, Bieniasz M, Wierzbicki A, Bambach BJ, Rokita H and Kozbor D: Targeting a mimotope vaccine to activating Fcgamma receptors empowers dendritic cells to prime specific $\mathrm{CD} 8^{+} \mathrm{T}$ cell responses in tumor-bearing mice. J Immunol 183: 6808-6818, 2009. 